\title{
Planning Method for Urban Subway Park-and-Ride Station and Parking Berth
}

\author{
Yi Cao ${ }^{1}$, Yi-xiao Wang $^{1 *}$, Zhong-zhen Yang ${ }^{2}$ \\ 1 Department of Traffic Engineering, School of Transportation Engineering, Dalian Jiaotong University, 116028 Dalian, \\ 794 Huanghe Road, People's Republic of China \\ 2 Department of Logistics management, Faculty of Maritime and Transportation, Ningbo University, 315211 Ningbo, \\ 818 Fenghua Road, People's Republic of China \\ * Corresponding author, e-mail: wangyixiao3704@djtu.edu.cn
}

Received: 26 February 2020, Accepted: 08 January 2021, Published online: 25 November 2021

\begin{abstract}
For satisfying the growing demand of parking in urban area and relieving traffic congestion in downtown, under the condition of urban subway park-and-ride (P\&R), the methods of site selection and scale calculation of parking lots are studied. Selecting Xi'an Rd. business circle in Dalian as study object, both survey and analysis of parking demand were conducted. Based on the principle of random equilibrium selection, the logit model of P\&R demand was constructed. Then the forecasting models of parking demand both in downtown and peripheral zones were proposed respectively. Using the minimum travel distance of vehicles as the objective function, site selection optimization model of P\&R station was constructed. The calculation methods of scale for parking lots in both downtown and P\&R station were also processed. For the case of Xi'an Rd. business circle, not only the site of P\&R station was planned, but the scale of parking berth was calculated. According to the plan and calculation, the total number of parking berth has increased from 3380 to 4011 . Among the planned berths, $75.7 \%$ are in the business circle and $24.3 \%$ in P\&R stations are outside downtown. Thus, the number of planned berths in the business circle has actually decreased by about $8 \%$. The research indicates that, for downtown with subway system, by reducing parking berths in downtown and increasing them in P\&R stations outside the urban area, this planning method is more beneficial to relieve the problems of parking and traffic congestion in downtown than traditional method. Keywords
\end{abstract}

traffic engineering, planning method, park-and-ride station, parking berth, logit model

\section{Introduction}

With the explosive growth of the number of private cars in cities, the problem of parking downtown is becoming increasingly prominent. This problem may have a negative influence on traffic to a large extent (Fu et al., 2020; $\mathrm{Fu}$ and Sayed, 2021). The traditional method for planning parking is based on traffic demand: a corresponding number of parking berths is planned in a region according to the parking demand acquired from parking forecasting and after considering the turnover rate and utilization rate of parking lots (Yuan et al., 2012). However, not only has that approach resulted in the appropriation of valuable urban land, it also has the insidious effect of stimulating traffic growth. Instead, the development of urban rail transit is leading to the new travelling mode of urban subway park and ride (P\&R). Naturally, people realize that some downtown parking berths should be relocated to subway
P\&R stations outside the urban area under the condition of urban subway. Not only would this approach save land resources in downtown, it would also encourage the public to travel using the P\&R mode and ease traffic pressure in downtown. As such, it is necessary to study and discuss the problems of scale calculation and location planning for the parking lots of an urban subway P\&R scheme.

To date, this problem has been studied by scholars both in China and internationally. Regarding selecting the P\&R travelling mode, Kadar Hamsa et al. (2014) investigated three parking lots at subway P\&R stations and two at bus P\&R stations. Those surveys showed utilization rates of parking lots at the subway P\&R stations in excess of $85 \%$; however, the utilization rates at the bus P\&R stations were lower. From analyzing comprehensively the factors influencing the selection of the P\&R mode, Memon et al. (2014) proposed 
a management strategy for increasing the ratio of this travelling mode. Based on a survey of travelling-mode tendencies and a logit model, Habib et al. (2013) studied how parking fees influence the selection of travelling mode. For the travelling modes of subway, car, and P\&R, Qin et al. (2012) constructed a travelling-mode selection model based on random equilibrium selection. Qin et al. (2008) also analyzed the relationship between parking fees and the choice of travelling mode. From analyzing the costs of every travelling mode and based on the same principle, Li and Zhang (2010) forecast the P\&R demand for Line 5 of the Beijing Subway. From a P\&R survey, Yun et al. (2012) not only produced a calibrated logit model but also analyzed how travelling time and cost influence the choice of travelling mode. Using data acquired from a wide network of parking sensors in Santander, Spain, Vlahogianni et al. (2016) presented a methodological framework for multiple-steps-ahead parking forecasting. Stieffenhofer et al. (2016) proposed and tested a method for measuring the parking efficiency of P\&R lots through an onsite audit. Regarding parking location, Aros-Vera et al. (2013) constructed a comprehensive linear-programming model, selecting the locations of $P \& R$ stations with the objective of maximizing parking-lot usage. Meanwhile, He and Yang (2014) proposed several alternative sites for the Beijing Subway; they compared schemes and selected an optimum one regarding accessibility, distance, and time. Based on the principles of equilibrium and optimal fare design, Wang and Qu (2017) proposed a planning method for railway stations. Pineda et al. (2016) proposed an integrated stochastic equilibrium model that considers both private automobile traffic and transit networks to incorporate the interactions between these two modes in terms of travel time and generalized costs. Using the same theory, Song et al. (2017) proposed an integrated planning framework for locating P\&R facilities and optimizing their capacities and transit service frequencies simultaneously.

Although there have been various studies on this topic both in China and internationally, most of the latter were focused on the probability of selecting the P\&R travelling mode rather than on the problem of forecasting parking demand downtown or in peripheral zones. In addition, few studies have considered how to calculate the parking capacity in those two regions under the condition of P\&R. Given this situation in the literature, models are constructed in the present paper for forecasting the parking demand downtown and in peripheral zones based on a survey and analysis of parking facilities and demand. A method of location selection and size calculation for P\&R stations is also studied. For urban subway transit, there is significant theoretical significance and practical application associated with being able to

- plan parking facilities downtown and at P\&R stations in peripheral zones reasonably and

- incentivize the P\&R travelling mode scientifically.

\section{Survey and analysis}

\subsection{Survey location}

Selecting the heartland of the Xi'an Road central business district (CBD) in Dalian, China as the survey object, a parking survey was conducted. As shown in Fig. 1, the survey

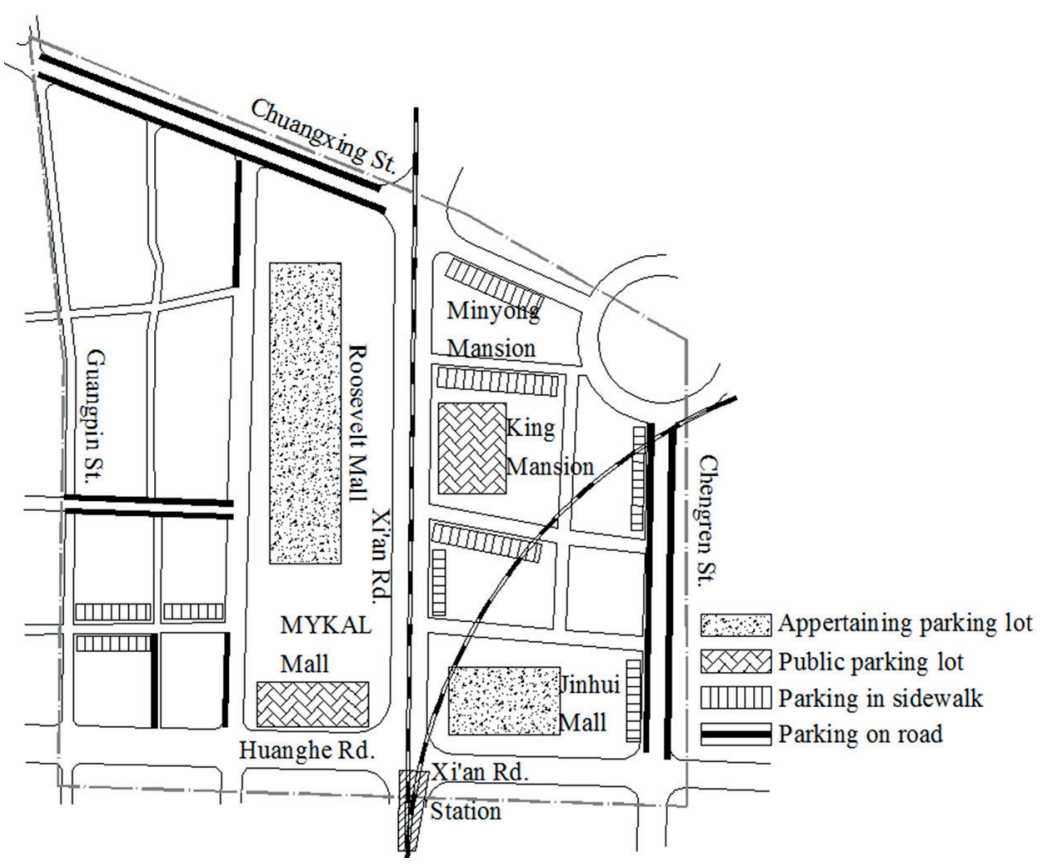

Fig. 1 Distribution of parking lots in survey region 
region is enclosed by Guangping Street, Chengren Street, Changxing Street, and Huanghe Road. This region is one of the most important commercial centers in Dalian, with crowded pedestrians and heavy traffic. It attracts a large number of passengers commuting across the city. However, there are also several thorny problems, such as high parking demand, insufficient parking berths, and the large influence of parking on the operating quality of dynamic traffic. In addition, this region is in the service radius of the transfer hub of Dalian metro lines 1 and 2. Therefore, the aforementioned location features and traffic characteristics make this region suitable for the present research.

A preliminary survey showed that the parking facilities in this region comprise public and private parking lots. In addition, to relieve the problem of insufficient parking facilities, parking on sidewalks or roads is allowed on non-arterial roads with lower traffic volume.

\subsection{Survey method}

The parking survey had two aims. The first was to acquire data pertaining to parking demand and parking supply. The second was to acquire data pertaining to the distribution of parking sources (i.e., where demand for parking was coming from) in this region. The survey was conducted from 9 o'clock to 19 o'clock on June 2, 2016.

Ten surveyors visited all parking lots in the region intermittently every $2 \mathrm{~h}$. These parking facilities include public parking lots, appertaining parking lots, and the areas of parking on sidewalks and roads. While investigating, the surveyors recorded the numbers of occupied and unoccupied parking berths. Another six investigators were stationed at the entrances of the two appertaining parking lots, the two public parking lots, and the two typical areas of parking in sidewalks and on roads. To calculate the parking turnover rate, they recorded continuously the number of vehicles driving into the parking lot. For the six aforementioned representative parking lots, if the drivers of the vehicles were encountered during either the visits or the survey interval, the surveyors asked them where they had come from before parking. Therefore, the survey of parking sources was an intermittent sampling survey.

\subsection{Data processing and analysis}

The survey led directly to the number of parking berths in each parking lot. From the numbers of cars parked in certain time, the average parking volume and the average utilization rates of the parking lots were calculated. For the six selected parking lots, from the total numbers of vehicles driving into them from 0900 to 1900, the parking turnover rates during this period were also calculated. The data for both parking demand and supply are given in Table 1. From the statistical results, the parking lots of Roosevelt Mall, MYKAL Mall, and Jinhui Mall are used mainly by shoppers, which is why the parking turnover rates for those areas are higher. However, the King Mansion parking area is used mainly by commuters or staffs, which is why its parking turnover rate is lower.

In the sample survey of parking sources in the six representative parking lots, 552 vehicles were investigated, giving a sampling rate of $3.22 \%$. After appropriate combining and integrating, the parking sources were determined as given in Table 2 .

Table 1 Parking facilities and demand

\begin{tabular}{|c|c|c|c|c|c|}
\hline Parking lot & Type & No. of berths & No. of cars parked & Utilization rate $(\%)$ & Turnover rate (vehicles/berth) \\
\hline Roosevelt Mall & Appertaining & 1,000 & 962 & 96.2 & 6.6 \\
\hline Jinhui Mall & Appertaining & 1,000 & 944 & 94.4 & 5.9 \\
\hline King Mansion & Private & 220 & 184 & 83.6 & 1.4 \\
\hline MYKAL Mall & Public & 70 & 60 & 85.7 & 5.5 \\
\hline Parking in sidewalk & Public & 306 & 272 & 88.9 & 2.5 \\
\hline Parking on road & Public & 712 & 662 & 93.0 & 3.1 \\
\hline
\end{tabular}

Table 2 Parking sources

\begin{tabular}{|c|c|c|c|c|c|}
\hline Parking source & No. of cars parked & Parking source & No. of cars parked & Parking source & No. of cars parked \\
\hline Xinghai & 28 & Zhangqian Road & 11 & Dongjia & 6 \\
\hline Heishijiao & 19 & Airport & 12 & Zhonghua Road & 9 \\
\hline University of Technology & 14 & Jinjia Street & 37 & Chunliu & 12 \\
\hline High-tech Park & 45 & Donggang & 15 & Songjia Road & 6 \\
\hline Bayi Road & 35 & Xinzhaizi & 9 & Quanshui & 6 \\
\hline Huanan Square & 44 & Dalian Petrochemica & 7 & Downtown & 219 \\
\hline Houyan & 9 & Zhongnan Road & 9 & Total & 552 \\
\hline
\end{tabular}




\section{Model and methodology}

\subsection{Logit model for P\&R demand}

For journeys outside the city, the key is to know how many people travel by car all the way and how many travel by subway P\&R. This is the problem of selecting the travelling mode, and it can be described by the traditional logit model. Based on the theory of random utility, the utility function for selecting one travelling mode is defined as $U_{i}$ and can be expressed as the sum of a fixed utility term $V_{i}$ and a random term $\varepsilon_{i}$, as Eq. (1) shows:

$U_{i}=V_{i}+\varepsilon_{i}, i=$ car or P\&R.

Assuming that the random term $\varepsilon_{i}$ of each utility function follows a double exponential distribution with the same parameter, the binomial logit model of P\&R demand can be acquired, as Eq. (2) shows (Habib et al., 2013):

$$
\begin{aligned}
& P_{\mathrm{P} \& \mathrm{R}}=\frac{\exp V_{\mathrm{P} \& \mathrm{R}}}{\exp V_{\mathrm{P} \& \mathrm{R}}+\exp V_{C A R}}, \\
& P_{\mathrm{P} \& \mathrm{R}}=1-P_{C A R},
\end{aligned}
$$

where $P_{\mathrm{P} \& \mathrm{R}}$ and $P_{C A R}$ are the probabilities of using P\&R and travelling by car all the way, respectively, as the mode of travel. Synthesizing Eqs. (2) and (3), we obtain Eq. (4).

$$
V_{\mathrm{P} \& \mathrm{R}}-V_{C A R}=\ln \frac{P_{\mathrm{P} \& \mathrm{R}}}{1-P_{\mathrm{P} \& \mathrm{R}}}
$$

Thus, which travelling mode is selected is determined by the difference between the fixed terms in the utility functions. This difference is related to the time saving $F$ and cost saving $C$ and should be linear with them, thus it can be expressed as Eq. (5):

$\ln \frac{P_{\mathrm{P} \& \mathrm{R}}}{1-P_{\mathrm{P} \& \mathrm{R}}}=\alpha F+\beta C+\gamma$,

where $F$ (unit: minutes) and $C$ (unit: CNY) are the time and cost savings, respectively, of using $P \& R$ comparing with travelling by car all the way. The terms $\alpha, \beta$, and $\gamma$ are the regressive parameters of the model.

To regress the above model, we must first investigate the travelling modes of cars in the region, thereby determining the travelling proportion $P_{\mathrm{P} \& \mathrm{R}}$ of the P\&R mode. Second, we calculate the time saving $F$ and cost saving $C$ of the P\&R travelling mode for each region, whereupon we determine the model parameters $\alpha, \beta$, and $\gamma$ by binary linear regression. Finally, we use Eq. (6) to calculate the probability of P\&R travelling in each region outside the urban area, namely:

$$
P_{\mathrm{P} \& \mathrm{R}}=\frac{1}{1+\exp (-\alpha F-\beta C-\gamma)} .
$$

\subsection{Parking demand of downtown and peripheral regions}

According to the planning concept of the present study, the parking demand in downtown and P\&R stations outside the urban area should be calculated after considering the travelling-mode selection and based on the survey of parking sources.

Considering the factors of parking convenience and economy, we reason that car drivers from downtown will not travel to a P\&R station outside the urban area and then travel back downtown by subway; we assign a probability of zero to that scenario. Thus, the downtown parking facilities serve two main forms of car use:

1. car journeys from downtown itself and

2. journeys from urban peripheral areas by car all the way.

The above analysis shows that the downtown parking demand $D_{0}$ (unit: vehicles/day) should be calculated as Eq. (7):

$D_{0}=\frac{1}{r}\left[N_{0}+\sum_{i=1}^{n} N_{i} \cdot\left(1-P_{i \mathrm{P} \& \mathrm{R}}\right)\right]$,

where $N_{0}$ (unit: vehicles/day) is the surveyed number of cars parked downtown, $N_{i}$ (unit: vehicles/day) is the surveyed number of cars parked from region $i$ outside the urban area, $P_{i \text { P\&R }}$ is the probability of selecting the P\&R mode to travel from region $i$ outside the urban area, and $r$ (unit: percent) is the sampling rate of the survey of parking sources. Based on a similar principle, a given region outside the urban area is taken as a source of journeys. The parking demand $D_{i}$ (unit: vehicles/day) of region $i$ outside the urban area is calculated by Eq. (8):

$D_{i}=\frac{N_{i} \cdot P_{i \mathrm{P} \& \mathrm{R}}}{r}$,

where, $D_{i}$ (vehicles/day) is the parking demand of the No. $i$ region outside urban area. We should note that the parking demand of downtown and the peripheral regions as calculated with Eqs. (7) and (8) cannot be deemed the scale of parking facilities in the region directly. The scale of parking facilities should be determined from not only the regional differences of parking utilization rates and turnover rates but also where the P\&R stations are located. 


\subsection{Method for selecting the locations of P\&R stations}

Considering the convenience of $P \& R$, the $P \& R$ demand of each source of journeys along a subway line is defined as the weight in the present research. The locations of P\&R stations are selected by minimizing the sum of weighted travelling distances of every source of journeys. Thus, the problem of selecting the location of a P\&R station along a subway line outside an urban area is described as follows.

There are $m$ stations along a subway line outside the urban area, with $n$ sources of journeys. The P\&R demand of source $\mathrm{i}$ of journeys is $D_{i}$. The shortest path from the centroid of source $i$ to subway station $j$ is $d_{i j}$, the value of which can be measured on electronic map. Thus, $K$ P\&R stations must be selected among the $m$ subway stations with the condition of minimizing the sum of weighted travelling distances from every source of journeys to P\&R, as shown in Fig. 2.

For this problem of location selection, the following method is proposed:

1. The decision vector of location selection is defined as $\boldsymbol{X}=\left[x_{1}, x_{2} \ldots x_{j} \ldots x_{m}\right]^{T}$, the elements of which must satisfy Eq. (9):

$$
x_{j} \in\{0,1\}, \sum_{j=1}^{m} x_{j}=K \text {. }
$$

Thus, the vector element $x_{j}$ is the decision variable that determines whether station $j$ is selected as a $P \& R$ station. $\mathrm{K}$ is the total number of $\mathrm{P} \& \mathrm{R}$ alternative stations along the subway line and should be acquired from urban planning bureau of the city.

2. The shortest-path matrix is constructed as $\boldsymbol{A}=\left[d_{i j}\right]_{n \times m}$, where $d_{i j}$ is the shortest travelling distance from the centroid of source $i$ to subway station $j$. Its value can be measured on the planning map.

3. To find the closest P\&R alternative station, the shortest-path matrix must be adjusted. For every source $i$ of journeys, when $x_{j}=1$, the minimum $d_{i j}$ in matrix $\boldsymbol{A}$ should be retained and the others should be replaced by zero. Thus a new matrix $\boldsymbol{A}^{*}$ is acquired.

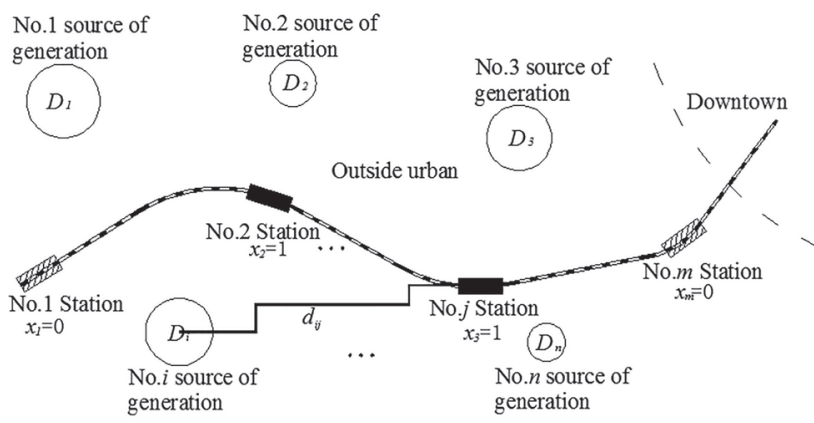

Fig. 2 Selecting the location of a park-and-ride (P\&R) station
4. $\boldsymbol{A}^{*} \cdot \boldsymbol{X}$ is calculated as the vector $\boldsymbol{B}=\left[b_{1}, b_{2} \ldots b_{n}\right]^{T}$.

5. For the subway stations and P\&R alternative stations, every possible value of the decision vector $\boldsymbol{X}$ should be assigned. For every decision vector, the weighted sum of travelling distance $L$ can be calculated according to Eq. (10):

$$
L=\sum_{i=1}^{n} D_{i} \cdot b_{i} .
$$

Selecting the minimum $L$, the corresponding decision vector $\boldsymbol{X}$ reflects the optimal locations of the P\&R stations.

\subsection{Method for calculating the scale of parking}

Based on the determined parking demand and considered the average utilization and turnover rates of the parking area, the total scale of downtown parking can be calculated by Eq. (11):

$F_{0}=\frac{D_{0}}{u_{0} \cdot t_{0}}$,

where $F_{0}$ is the total number of downtown parking berths, $u_{0}$ (unit: percent) is the average utilization rate of downtown parking lots, and $t_{0}$ (unit: vehicles/day) is the turnover rate of downtown parking lots.

For the scale of parking at a P\&R station outside the city, as well as the aforementioned factors, the parking demand of journey sources attracted to that P\&R station should also be considered after the location of the P\&R station has been determined. In fact, in step 3) of the method for locating P\&R stations, the distinctive work of parking source in every P\&R station has been done. When $x_{j}=1$, if the element $d_{i j}$ in matrix $\boldsymbol{A}$ is retained, then the parking of journey source $i$ is attracted to $\mathrm{P} \& \mathrm{R}$ station $j$; however, if $d_{i j}$ in matrix $\boldsymbol{A}$ is replaced by zero, then this journey source is not attracted to the P\&R station. Thus, for the scale of P\&R station $j$, not all parking demand $D_{i}$ should be added together: only if $d_{i j}$ in matrix $\boldsymbol{A}$ is not replaced should the corresponding $D_{i}$ be added. Thus, the scale of parking at P\&R station $j$ can be recorded as $F_{j}$ and calculated by Eq. (12):

$F_{j}=\frac{x_{j} \cdot \sum_{\substack{i=1 \\ d_{i j} \neq 0}}^{n} D_{i}}{u_{j} \cdot t_{j}}$,

where $F_{j}$ is the number of parking berths at subway station $j, u_{j}$ (unit: percent) is the parking utilization rate of subway station $j$, and $t_{j}$ (unit: vehicles/day) is the parking turnover rate of subway station $j$. 


\section{Application and discussion}

Using the aforementioned methods for locating P\&R stations and calculating the scale of parking, the parking facilities of the Xi'an Road CBD and its corresponding P\&R stations outside the urban area are planned according to the data acquired from the parking survey. The planning results are then compared with the present situation with regard to parking facilities.

\subsection{Forecast parking demand}

A questionnaire survey was conducted into the $P \& R$ demand in the four journey sources along the western segment of metro line 1, from which the $P_{\mathrm{P} \& \mathrm{R}}$ data of every journey source are acquired. The parameters of the P\&R forecasting model are then calculated using Eq. (5) and are given in Table 3.

From the data in Table 3, the parameters of the P\&R demand forecasting model are acquired by two element linear regression as $\alpha=0.0026, \beta=0.0958$, and $\gamma=-2.6621$. From the model regression parameters, the P\&R demand probabilities of the other peripheral journey sources in Dalian are calculated using Eq. (6). From the P\&R demand data of every peripheral journey source and the survey data listed in Table 2, the parking demand of downtown and every peripheral journey source is calculated and given in Table 4.

\subsection{Selected locations of P\&R stations}

Selecting the western segment of Dalian metro line 1 as the case in question, the locations of $P \& R$ stations are selected and planned by the location method discussed herein. There are four journey sources in this region:

1. High-tech Park,

2. the University of Technology,

3. Heishijiao, and

4. Xinghai from west to east.

There are seven metro stations on this segment of metro line 1 , and these are the possible sites of $P \& R$ stations in this case, from which 2 must be selected, according to the condition of land use.

According to the present location method, there are seven elements in the decision vector of location selection, two of which are unity and the others are zero. For all possibilities, there are 21 groups of value about $\boldsymbol{X}$. The shortest path from the centroid of each journey source to each metro station is measured from the planning map. Thus, the shortest-path matrix $\boldsymbol{A}$ is acquired as:

$$
\boldsymbol{A}=\left[\begin{array}{lllllll}
2.2 & 1.4 & 2.2 & 3.6 & 5.0 & 5.8 & 6.2 \\
4.5 & 2.6 & 1.9 & 2.3 & 3.6 & 4.5 & 5.0 \\
6.6 & 4.6 & 3.4 & 2.1 & 1.0 & 1.6 & 2.1 \\
7.2 & 5.5 & 4.3 & 3.0 & 1.7 & 1.0 & 0.9
\end{array}\right]^{T} .
$$

Table 3 Regional characteristic parameters of $\mathrm{P} \& \mathrm{R}$

\begin{tabular}{lcccc}
\hline Region & Time saving F [min] & Cost saving C [CNY] & P\&R proportion PP\&R [\%] & $\ln \frac{P_{\text {P\&R }}}{1-P_{\text {P\&R }}}$ \\
\hline Xinghai & -5 & 6 & 11 & -2.091 \\
Heishijiao & 3 & 10 & 15 & -1.735 \\
University of Technology & 8 & 16 & 26 & -1.046 \\
High-tech Park & 10 & 20 & 32 & -0.754 \\
\hline
\end{tabular}

Table 4 Forecasted parking demands

\begin{tabular}{lccccc}
\hline Parking source & $\begin{array}{c}\text { Parking demand } \\
\text { [vehicles per day] }\end{array}$ & Parking source & $\begin{array}{c}\text { Parking demand } \\
\text { [vehicles per day] }\end{array}$ & Parking source & $\begin{array}{c}\text { Parking demand } \\
\text { [vehicles per day] }\end{array}$ \\
\hline Xinghai & 95 & Zhangqian Road & 78 & Dongjia & 43 \\
Heishijiao & 91 & Airport & 69 & Zhonghua Road & 65 \\
University of Technology & 108 & Jinjia Street & 179 & Chunliu & 56 \\
High-tech Park & 458 & Donggang & 87 & Songjia Road & 33 \\
Bayi Road & 251 & Xinzhaizi & 92 & Quanshui & 54 \\
Huanan Square & 507 & Dalian & 34 & Downtown & 14,656 \\
Houyan & 144 & Zhongnan Road & 43 & Total & 17,143 \\
\hline
\end{tabular}


For every possible decision vector $\boldsymbol{X}$, the present P\&R location method is implemented from step 1) to step 5). After 21 iterations, the decision vector $\boldsymbol{X}=\left[\begin{array}{lllllll}0 & 1 & 0 & 0 & 0 & 1 & 0\end{array}\right]^{T}$ is obtained and the sum of travelling distance multiplying parking demand, $L$ is minimized as 1,162.6 (vehicles $\cdot \mathrm{km} /$ day). Therefore, the two P\&R stations should be those at High-tech Park and Xinghai Park, and the P\&R parking lots should also be at these two stations. Thus, the sum of travelling distance multiplying P\&R demand of each journey source along this line segment is minimized, as shown in Fig. 3. The same method can be used to select the locations of P\&R stations for other subway lines outside the downtown area. Thus, for the Xi'an Road CBD, a location plan of subway P\&R all over the city can be acquired.

\subsection{Calculated scale of parking area}

Having determined the parking demand of every region and the locations of every peripheral P\&R station, the scales of parking required downtown and outside the urban area are calculated using Eqs. (11) and (12). For this, the average utilization and turnover rates of downtown parking are acquired from the parking survey as $u_{0}=93.2 \%$ and $t_{0}=5.18$ (vehicles/day), respectively. From the planning standard, the average expected utilization and turnover rates of planned parking outside the urban area are $u_{i}=85 \%$ and $t_{i}=3$ (vehicles/day), respectively. The planned locations of every P\&R station are shown in Fig. 4, and the corresponding numbers of parking berths are given in Table 5 .

Compared with the forecast figure of 4,011 of the proposed scheme, there are currently only 3,308 parking berths in Xi'an Road CBD. Not only do those parking berths occupy precious downtown land, they also stimulate car travel to downtown from outside the urban area.

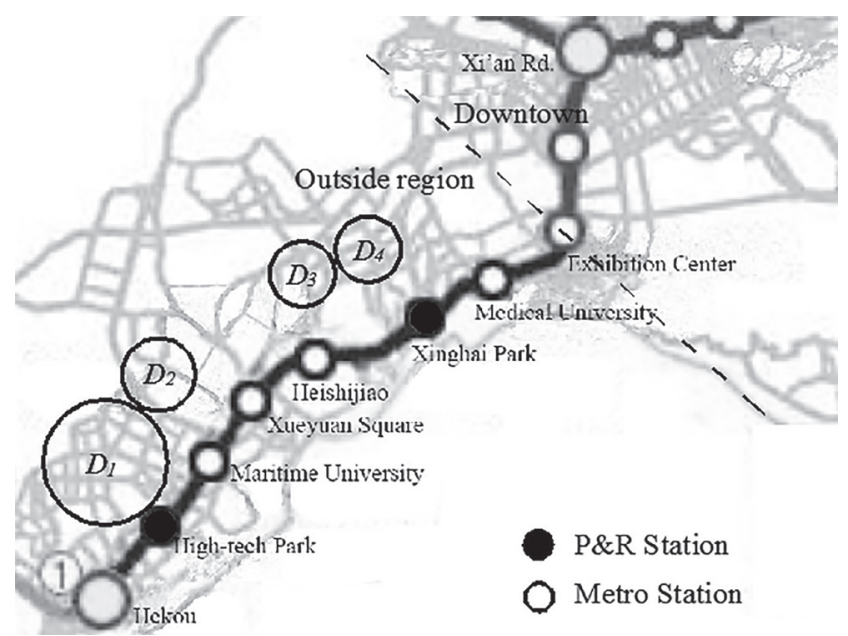

Fig. 3 The P\&R stations on the western segment of Metro line 1

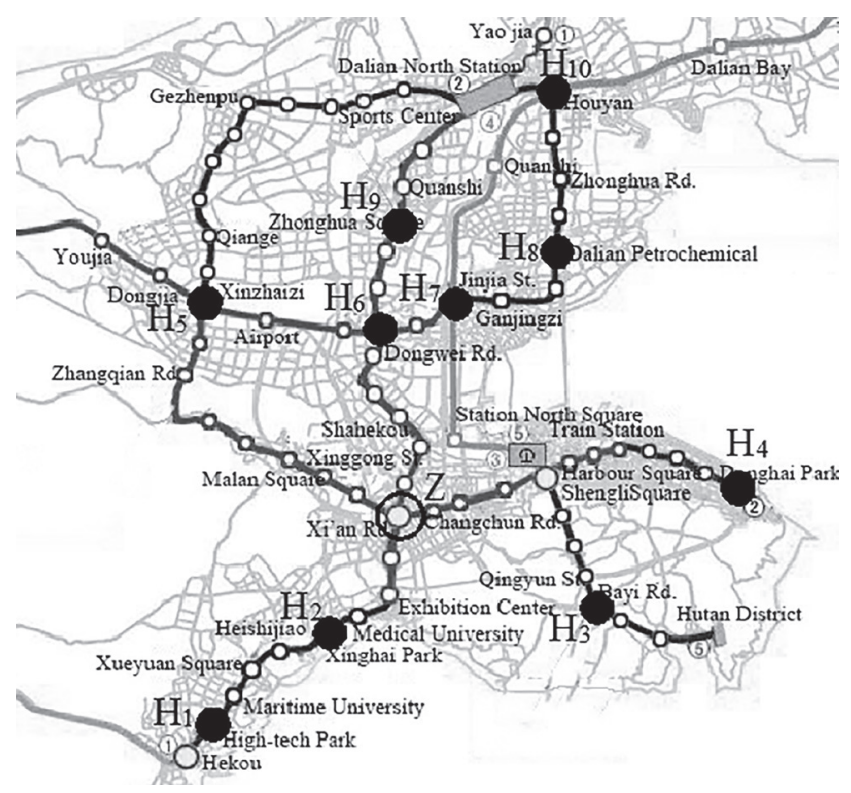

Fig. 4 Subway P\&R stations of Xi'an Road central business district

Table 5 Forecast scale of parking lots

\begin{tabular}{|c|c|c|c|c|c|}
\hline Grade & $\begin{array}{l}\text { Station } \\
\text { name }\end{array}$ & $\begin{array}{l}\text { Number } \\
\text { of berth }\end{array}$ & Grade & Station name & $\begin{array}{l}\text { Number } \\
\text { of berth }\end{array}$ \\
\hline $\mathrm{H} 1$ & $\begin{array}{l}\text { High-tech } \\
\text { Park }\end{array}$ & 222 & $\mathrm{H} 7$ & Jinjia Street & 70 \\
\hline $\mathrm{H} 2$ & $\begin{array}{l}\text { Xinghai } \\
\text { Park }\end{array}$ & 73 & $\mathrm{H} 8$ & $\begin{array}{c}\text { Dalian } \\
\text { Petrochemica }\end{array}$ & 39 \\
\hline H3 & Bayi Road & 115 & H9 & $\begin{array}{l}\text { Zhonghua } \\
\text { Square }\end{array}$ & 220 \\
\hline $\mathrm{H} 4$ & $\begin{array}{l}\text { Donghai } \\
\text { Park }\end{array}$ & 34 & $\mathrm{H} 10$ & Houyan & 56 \\
\hline H5 & Xinzhaizi & 111 & Z & Xi'an Road & 3,036 \\
\hline H6 & $\begin{array}{l}\text { Dongwei } \\
\text { Road }\end{array}$ & 35 & Total & - & 4,011 \\
\hline
\end{tabular}

However, although the proposed scheme involves 4,011 parking berths servicing the Xi'an Road CBD, only 3,036 of those are actually located therein. The other 975 parking berths are at the subway P\&R stations outside the city. Therefore, the proposed scheme can incentivize people to use the P\&R travelling mode and relief downtown traffic pressure to a certain extent.

We note that the planned P\&R subway stations and their scale in the present case are solely for the parking services of the Xi'an Road CBD rather than for the entire city. Only if this planning method is applied to all the downtown CBDs can the acquired plan of parking facilities layout and scale be serviced for the entire city. 


\section{Conclusions}

1. For cities with a subway system, the downtown parking demand and those of the peripheral journey sources should be forecast considering the possibilities of subway P\&R in every region. The location of every P\&R station and the scale of parking lots in every region should be planned after determining the parking demand and origins of every region.

2. For this method of planning parking, under the premise of considering the subway P\&R demand of every region, some of downtown parking provision is located at subway P\&R stations outside the city. Compared with the traditional method, this planning method leads to fewer downtown parking berths and correspondingly more parking berths at subway P\&R stations. Not only does this approach incentivize people to use subway $P \& R$, it can also relieve downtown traffic congestion to a certain extent.

Limited by the survey conditions, when calculating the scales of every parking lot, the parking utilization and

\section{References}

Aros-Vera, F., Marianov, V., Mitchell, J. E. (2013) "p-Hub approach for the optimal park-and-ride facility location problem", European Journal of Operational Research, 226(2), pp. 277-285. https://doi.org/10.1016/j.ejor.2012.11.006

Fu, C., Sayed, T. (2021) "Multivariate Bayesian hierarchical Gaussian copula modeling of the non-stationary traffic conflict extremes for crash estimation", Analytic Methods in Accident Research, 29, Article number: 100154.

https://doi.org/10.1016/j.amar.2020.100154

Fu, C., Sayed, T., Zheng, L. (2020) "Multivariate Bayesian hierarchical modeling of the non-stationary traffic conflict extremes for crash estimation", Analytic Methods in Accident Research, 28, Article number: 100135 .

https://doi.org/10.1016/j.amar.2020.100135

Habib, K. N., Mahmoud, M. S., Coleman, J. (2013) "Effect of Parking Charges at Transit Stations on Park-and-Ride Mode Choice: Lessons Learned from Stated Preference Survey in Greater Vancouver, Canada", Transportation Research Record, 2351(1), pp. $163-170$.

https://doi.org/10.3141/2351-18

He, Y. J., Yang, X. K. (2014) "北京市停车换乘设施的规划与选址研究" (Planning and Selecting Locations of Park-and-Ride Facilities in Beijing), 交通科技 (Transportation Science \& Technology), 263(2), pp. 142-145. (in Chinese) https://doi.org/10.3963/j.issn.1671-7570.2014.02.044

Kadar Hamsa, A. A., Syed Adnan, A. A., Khalid, U. A. (2014) "Analysis of Parking Usage at the Park and Ride Facility in Klang Valley, Malaysia", WIT Transactions on the Built Environment, 138, pp. 179-193.

https://oi.org/10.2495/UT140161 turnover rates were selected according to planning standard rather than from measured data. As further research, we suggest calculating those indices from a survey once the subway P\&R stations have been selected.

\section{Acknowledgement}

This research was supported by the National Natural Science Foundation of China (grant No. 11702049), the Scientific Research Funding Project of Liaoning Provincial Education Department in 2020 (grant No. JDL2020017), the Educational Science Planning Project of Liaoning Province (grant No. JG20DB69), the Research Project on Economic and Social Development of Liaoning Province in 2022 by the Liaoning Provincial Federation Social Science Circles (grant No. 20221slybkt-022) and the 2021 Project of Dalian Academy of Social Sciences (grant No. 2021dlsky050).

The parking data is investigated and collected by 6 postgraduates and 60 senior students of the university of corresponding author, which is gratefully acknowledged. We are also grateful to the editors and anonymous reviewers for their suggestions, comments, and advice.

Li, Y., Zhang, X. Y. (2010) "北京市地铁5号线天通苑地区停车换乘需求 预测" (Park \& Ride demand forecasting at Tiantongyuan area along Beijing subway line five), 城市交通, 8(5), pp. 57-64. (in Chinese) https://doi.org/10.13813/j.cn11-5141/u.2010.05.011

Memon, I. A., Madzlan, N., Talpur, M. A. H., Hakro, M. R., Chandio, I. A. (2014) "A Review on the Factors Influencing the Park-and-Ride Traffic Management Method", Applied Mechanics and Materials, 567, pp. 663-668. https://doi.org/10.4028/www.scientific.net/AMM.567.663

Pineda, C., Cortés, C. E., Jara-Moroni, P., Moreno, E. (2016) “Integrated traffic-transit stochastic equilibrium model with park-andride facilities", Transportation Research Part C: Emerging Technologies, 71, pp. 86-107. https://doi.org/10.1016/j.trc.2016.06.021

Qin, H. M., Guan, H. Z., Yin, H. H. (2008) "停车收费价格对居民出行 方式选择行为的影响研究——以北京市居民小汽车、公交、出租 车选择行为为例" (A study of the effect of parking price on the mode of inhabitant trip behavior-with the cars, public transit and taxi in Beijing as an example), 土木工程学报, 41(8), pp. 93-98. (in Chinese) https://doi.org/10.15951/j.tmgcxb.2008.08.003

Qin, H. M., Guan, H. Z., Pan, X.S. (2012) "基于随机连续平衡模型的停 车换乘需求" (Park and ride demand based on stochastic continuum equilibrium model), 吉林大学学报(工学版), 42(2), pp. 322-326. (in Chinese) https://doi.org/10.13229/j.cnki.jdxbgxb2012.02.035

Song, Z. Q., He, Y., Zhang, L. H. (2017) "Integrated planning of parkand-ride facilities and transit service", Transportation Research Part C: Emerging Technologies, 74, pp. 182-195. https://doi.org/10.1016/j.trc.2016.11.017 
Stieffenhofer, K. E., Barton, M., Gayah, V. V. (2016) "Assessing parkand-ride efficiency and user reactions to parking management strategies", Journal of Public Transportation, 19(4), pp. 75-92. https://doi.org/10.5038/2375-0901.19.4.5

Vlahogianni, E. I., Kepaptsoglou, K., Tsetsos, V., Karlaftis, M. G. (2016) "A Real-Time Parking Prediction System for Smart Cities", Journal of Intelligent Transportation Systems, 20(2), pp. 192-204. https://doi.org/10.1080/15472450.2015.1037955

Wang, S. A., Qu, X. (2017) "Station choice for Australian commuter rail lines: Equilibrium and optimal fare design", European Journal of Operational Research, 258(1), pp. 144-154.

https://doi.org/10.1016/j.ejor.2016.08.040
Yuan, H. Z., Feng, Z. X., Jian, X. P., Liu, J. (2012) "城市中心区域小汽 车停车设施选择模型" (Selection Model of Car Parking Facility in Urban Central Region), 公路交通科技, 29(10), pp. 137-141. (in Chinese) https://doi.org/10.3969/j.issn.1002-0268.2012.10.024

Yun, M. P., Liu, X. W., Chen, Z. H., Yang, X. (2012) "通勤出行中停车换 乘选择行为分析与建模" (Analysis and Modeling of Park and ride choice Behavior in Commuting Travel), 同济大学学报(自然科学 版), 40(12), pp. 1825-1830. (in Chinese) https://doi.org/10.3969/j.issn.0253-374x.2012.12.014 